\title{
Monitoring of structurally controlled deformations at the Kanmantoo copper mine
}

\author{
BJ Hutchison Hillgrove Resources Limited, Australia \\ J Chambers Maptek Pty Ltd, Australia
}

\begin{abstract}
The Kanmantoo Copper Mine in the Adelaide Hills of South Australia was operated by Hillgrove Resources Limited from 2010-2019. The latest Giant Pit was a $360 \mathrm{~m}$ deep cutback with a $300 \mathrm{~m}$ high inter-ramp slope that had been steepened from $45^{\circ}$ from the previous Kavanagh cutback to $57^{\circ}$. The western wall was monitored by various Maptek Sentry Systems over three years from 2016 to 2019. During this time, the wall underwent significant relaxation and encountered multiple rockfalls; the latter which increased in size and frequency as the pit bottom was approached.
\end{abstract}

Maptek laser scanners were positioned at various locations to monitor the wall over the three years. Sentry was used to provide real-time monitoring and alarming capabilities. The Sentry laser scan data captured was analysed in Maptek PointStudio, to remotely map geological structures and identify rockfalls. These rockfalls ranged in size from several kilograms to more than 2,000 t. PointStudio was used to create a report from this data showing the complete mine life dilation and rockfalls that occurred during this period.

This paper discusses the deformation history of the west wall, the relationship of these movements to the geological structure and to various rockfalls that occurred during the latter excavation stages.

Keywords: steep wall mining, laser deformation monitoring, remote geologic structural mapping, rockfalls, mine life dilation

\section{Introduction}

The Kanmantoo Copper Mine in the Adelaide Hills of South Australia was mined with open cut methods by Hillgrove Resources Limited (HGO) from 2010-2019. The latest Giant Pit was a $360 \mathrm{~m}$ deep cutback, with aggressively steepened walls compared to the previous Kavanagh pit. For example, the $300 \mathrm{~m}$ high western wall inter-ramp slope angle (IRSA) was steepened from 45 to $57^{\circ}$ (Figure 1 ). The justification for adopting this aggressive design on the western wall is discussed elsewhere (Hutchison et al. 2017, 2020). The northern wall, which cut across the predominant steeply dipping north-south striking structures, was also steepened to an IRSA of $68^{\circ}$.

Laser scanning at Kanmantoo began in 2014 as Maptek was researching and developing their commercial systems. The west wall was intermittently monitored from various positions by several Maptek Sentry Systems (Sentry) over three years from 2016 to 2019. For much of the time, Sentry was used to provide real-time monitoring and alarming capabilities. Despite being monitored from several locations over various time frames, all the laser scanner data was compiled in PointStudio software (Maptek, 2020) into a single database to observe the long-term deformation history.

The laser scan data was also analysed in PointStudio to remotely map geological structures and identify rockfalls. These rockfalls ranged in size from several tens of kilograms to more than 2,000 $t$ and accelerated in size and frequency as the pit bottom was approached.

This paper discusses the deformation history of the west wall, the relationship of these movements to the geological structure and to various rockfalls that occurred during the latter excavation stages as compiled by PointStudio and Sentry. 


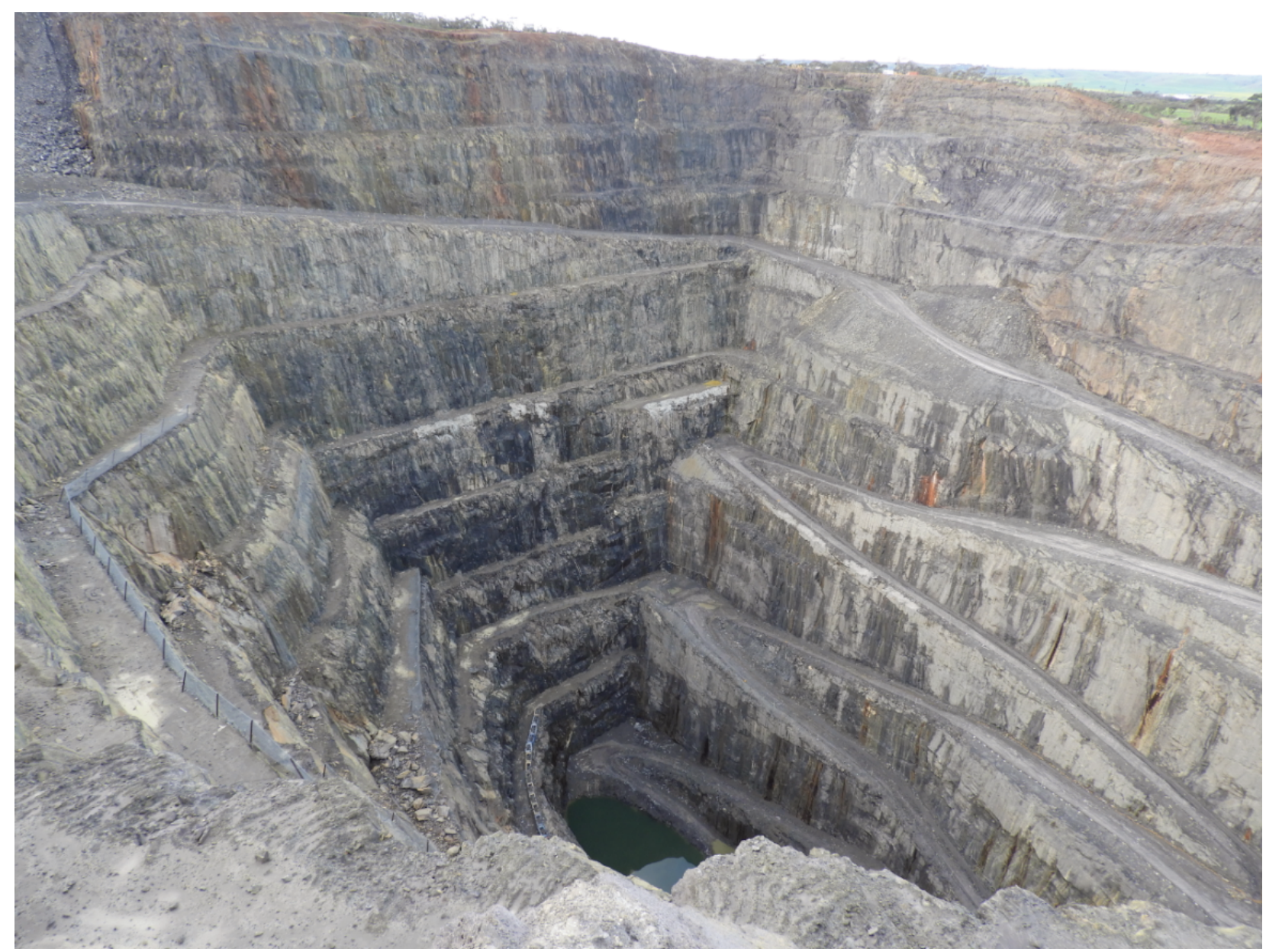

Figure 1 Giant pit (looking northeast)

\section{$2 \quad$ Slope monitoring systems}

The west wall of Giant Pit was monitored by several laser scanners and an IDS IBIS-FM slope stability radar during various periods from February 2016 through to June 2019. Critical alarm monitoring was specifically carried out by both types of monitoring systems but the rapid brittle failures that occurred were difficult to consistently detect and alarm with either method. An example of a successful laser monitoring detection is discussed in Section 3.3.

Long-term deformation monitoring was very successful using both systems. The IBIS-FM 'subsampling' analysis was, however, dependent on a continuous radar operation to determine long-term dilation. If the radar system was shut down, and/or moved and later returned, then any movement during that shutdown period went undetected. The laser scanner system, however, does not require continuous operation. Each scan collected a point cloud of data from which a unique digital terrain model (DTM) is created. Long-term dilation is calculated in PointStudio by comparing the DTMs to each other and then measuring the differences between them to identify areas that have moved.

The Maptek Sentry system can operate in a variety of modes. At Kanmantoo, Hillgrove deployed long-term pillar mounted systems operating in a fixed, continuous monitoring mode (HMS, Figure 2a), a trailer-mounted deployable monitoring system mode (DMS, Figure $2 b$ ) and rapidly deployed tripod-mounted system modes (Patrol, Figures 2c and 2d). 


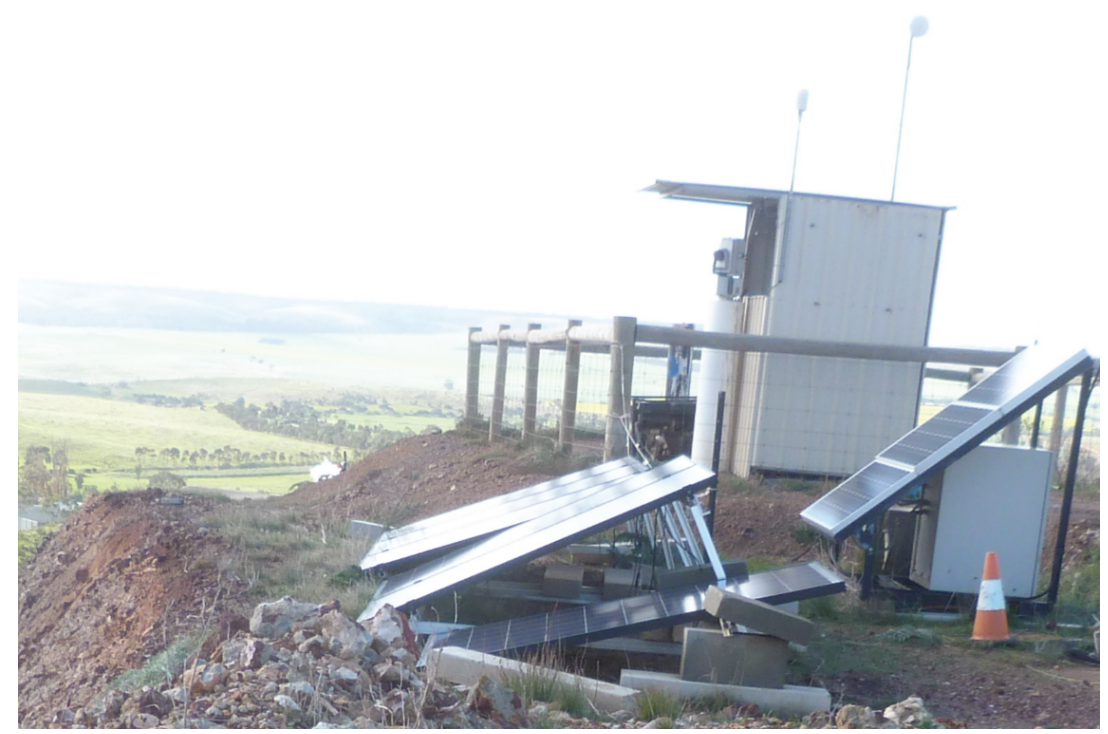

(a)

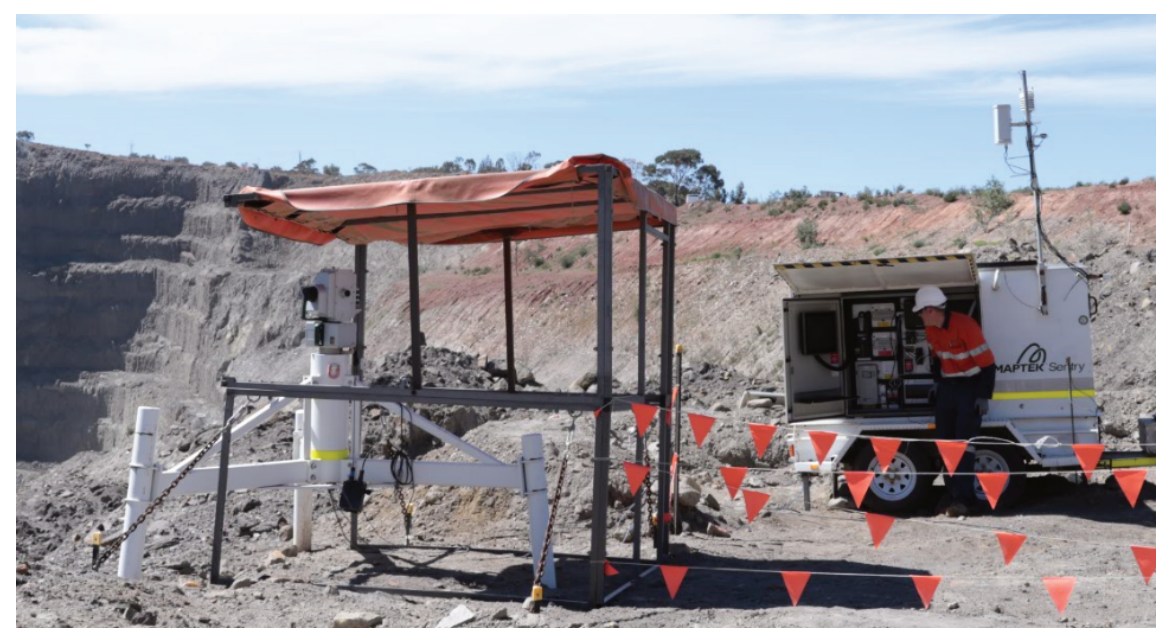

(b)

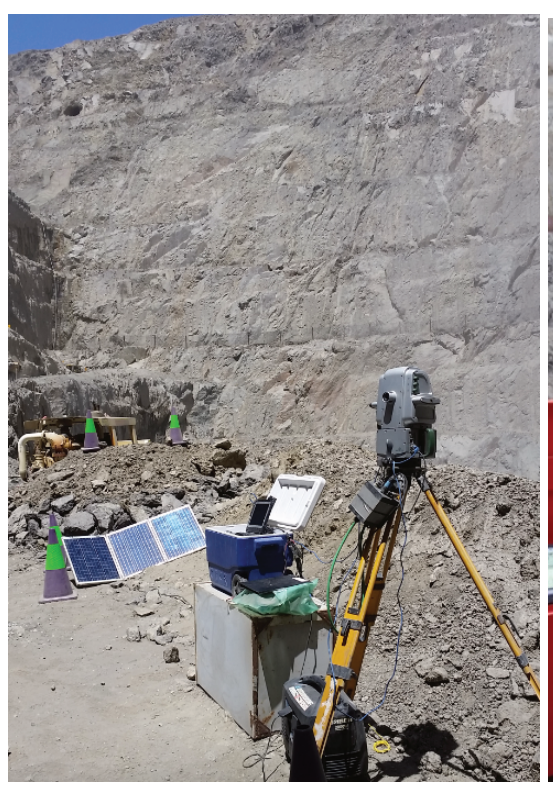

(c)

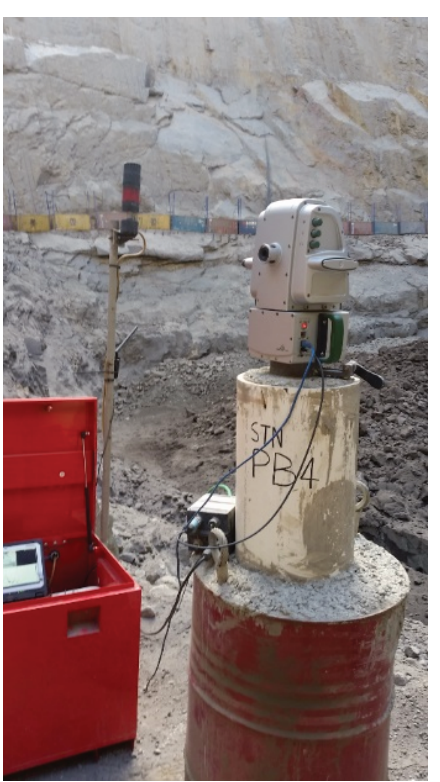

(d)

Figure 2 Interim Sentry Patrol \& XR3 in-pit setups 
After the initial periodic monitoring from a tripod at Kanmantoo in 2014, Maptek developed a fully contained Maptek Sentry DMS system (Figure 3).

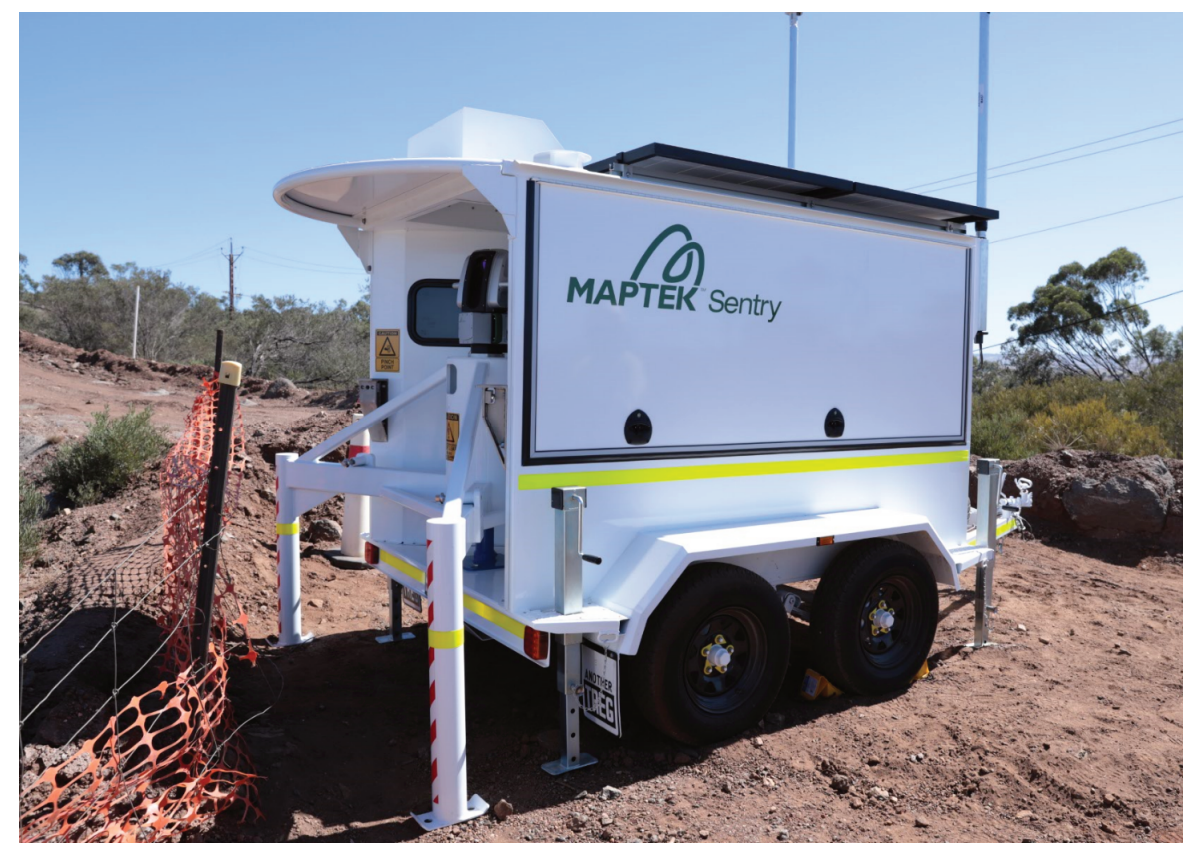

Figure 3 Maptek Sentry DMS

In 2016, it was never anticipated-or at least it was not the main intention-to use the laser data collected for long-term studies of the Giant Pit. If so, then the data would have been captured in a more controlled way. It was not until January 2018 that a dedicated monitoring station was established on the southeast crest of the pit and even then, two different instruments (Maptek 8820 and XR3 laser scanners) were used at different times. As discussed later, the various ad hoc sets of data have been successfully compiled to calculate the long-term dilation history of the west wall.

\section{$3 \quad$ Laser scanning}

\subsection{General}

The basics of the Maptek laser scanning techniques are described in Hutchison \& Howarth (2015). Essentially, a laser scan results in a point cloud, from which a DTM can be formed. The detail of the DTM is dependent on the resolution of the scan; typically taken at res 2,4 or 8 . Greater detail is achieved from the higher resolution scans, which is offset by a longer scanning time.

Maptek software utilises this data in several ways but for this paper, we have used two specific hardware/software packages:

1. Maptek Sentry.

2. Maptek PointStudio.

Sentry systems comprise dedicated hardware and software components that continually scan and analyse specified areas. The software compiles the data and then compares the data from scan to scan to determine areas of movement that are typically presented in a heat map of displacement or velocity. The software allows for setting movement thresholds and sending out alarms to specified personnel when the thresholds are exceeded.

PointStudio is a point cloud processing software package that allows individual scans to be analysed for applications such as end of month pit/stockpile surveys, pre/post-blast surveys, geological mapping, underground surveys and geotechnical analyses. 


\subsection{Scanning locations in Giant Pit}

As noted previously, several laser scanning locations were used during the years between 2016 and 2019 as the Giant Pit was developed. The majority of these were used in Sentry mode. The scanner locations and the types of scanners employed are summarised in Figure 4. Scanning locations from pit crests is often the most desirable as the equipment can be kept out of the way of operations and usually allows for the broadest coverage. Communications are also often more easily maintained from pit crests. At Kanmantoo, mobile telephone coverage was used to remotely dial into the system computer/s which collected and analysed the continuous scans.

As pits deepen, it is often difficult for laser scanning to acquire data at the lower levels due to line-of-site issues with crests and underlying berms. At Kanmantoo, the scanner located on the west wall was elevated and tilted up (Figure 5) to allow the scanner to 'see' deeper into the pit. This scanner operated in this mode for over six months with no operational issues.

At times, it may also be more advantageous to scan from the lower levels, or down on the pit floor itself, to provide more direct line of sight to wall movements, which tend to move the most in a down-dip direction. The two lower pit locations in Figure 4 were utilised for that purpose, setting up in Patrol mode, in the final few months of operation. The interim XR3 laser scanner setups in Figures $2 \mathrm{c}$ and $2 \mathrm{~d}$ were quickly established when wall movements were detected by a crest laser scan system. Remote communications were achieved through an antenna tied into one of the crest scanner systems.

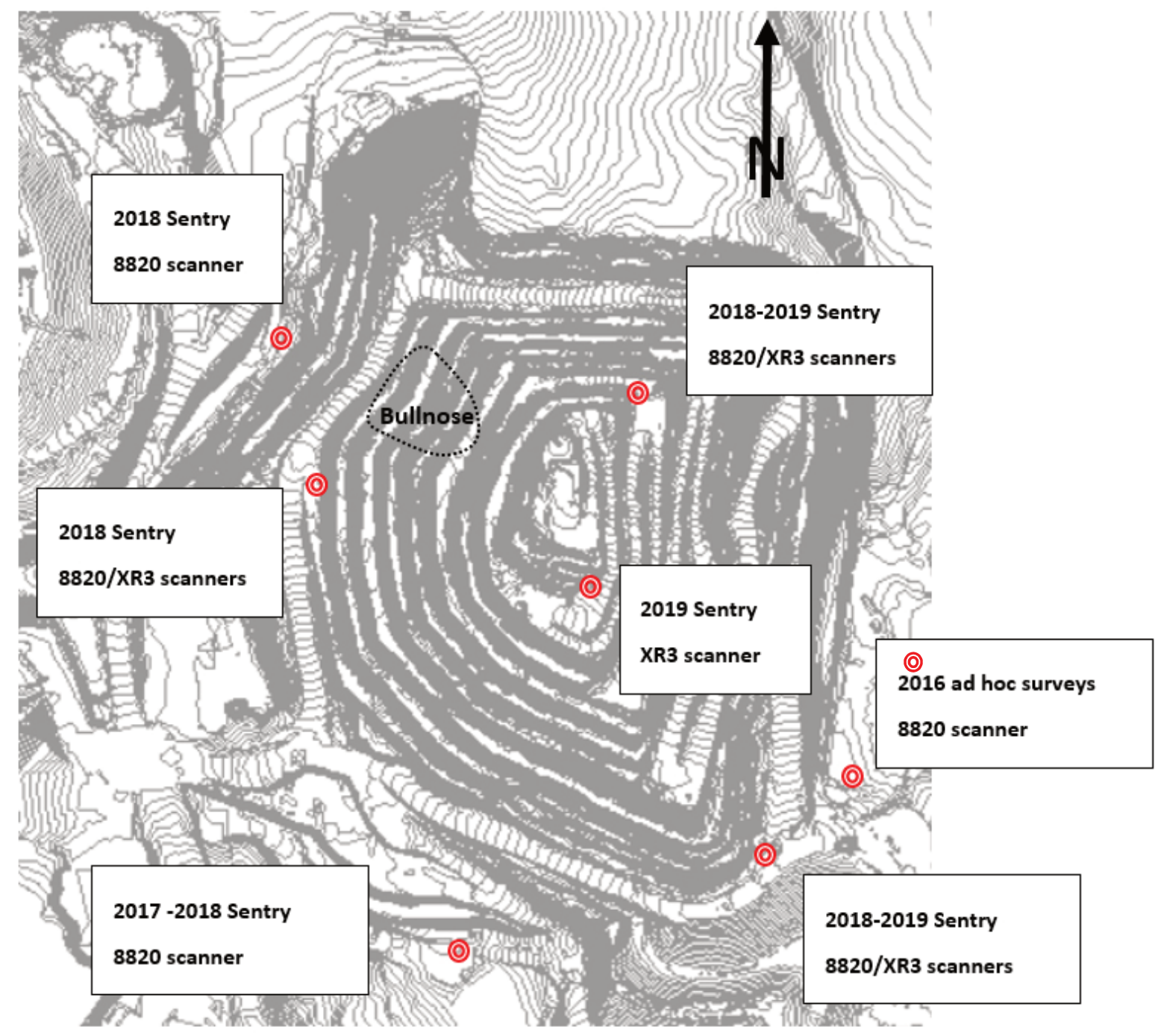

Figure 4 Giant Pit laser scanning positions 


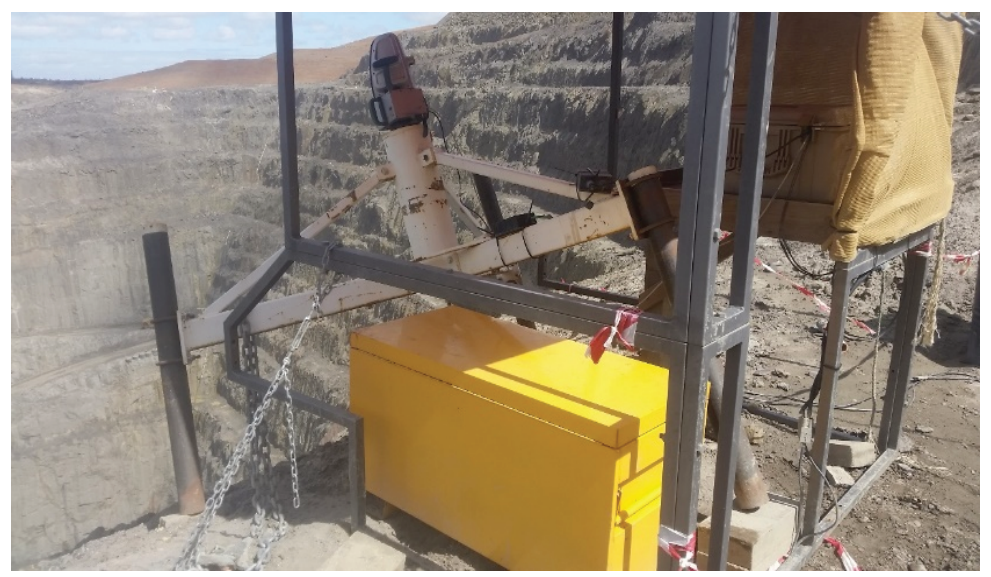

Figure 5 West wall scanner tilted to scan deep into the pit

\subsection{Critical alarm monitoring}

The Sentry DMS laser scanning system was successfully used to detect and monitor rockfall RF872 (Figure 6), which was a 2,464 t rockfall that occurred on 10 May 2019 during a period of heavy rain. The failure path of the fall can be seen in Figure 7 and further discussion on the consequences of the failure on underlying rockfall control structures can be found in Hutchison et al. (2020). Due to the rain, the pit had been closed for the previous 24 hours so no personnel were exposed to the rockfall risk. The effects of rainfall can be seen on the scan record (Figure 6) where the displacement values are interrupted due to lack of usable scan data.

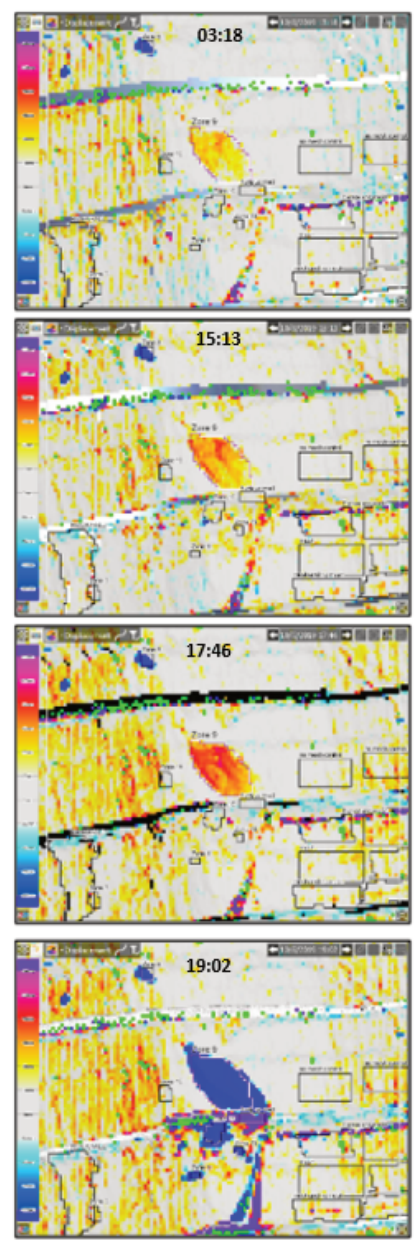

(a)
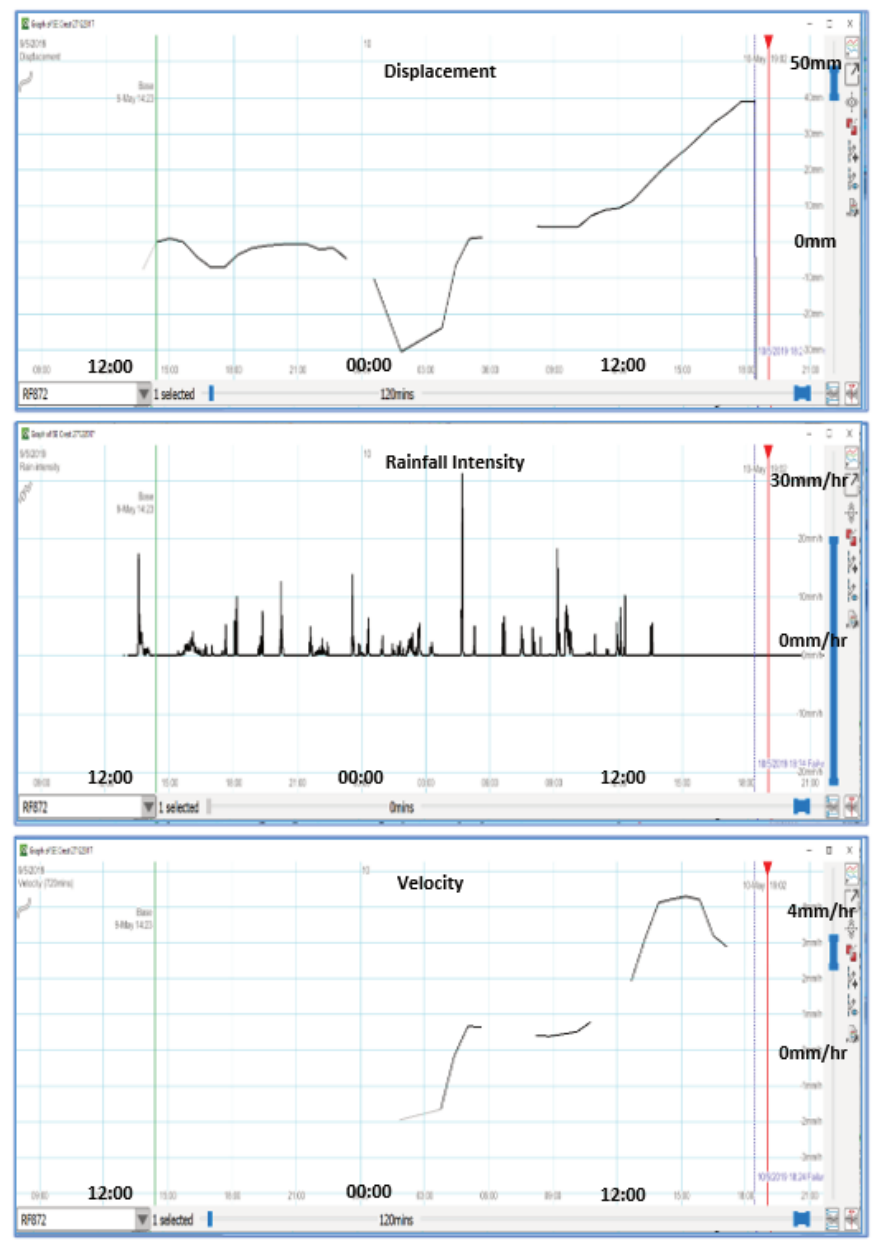

(b)

Figure 6 RF872 Sentry monitoring record. (a) Heat maps; and (b) Plots 


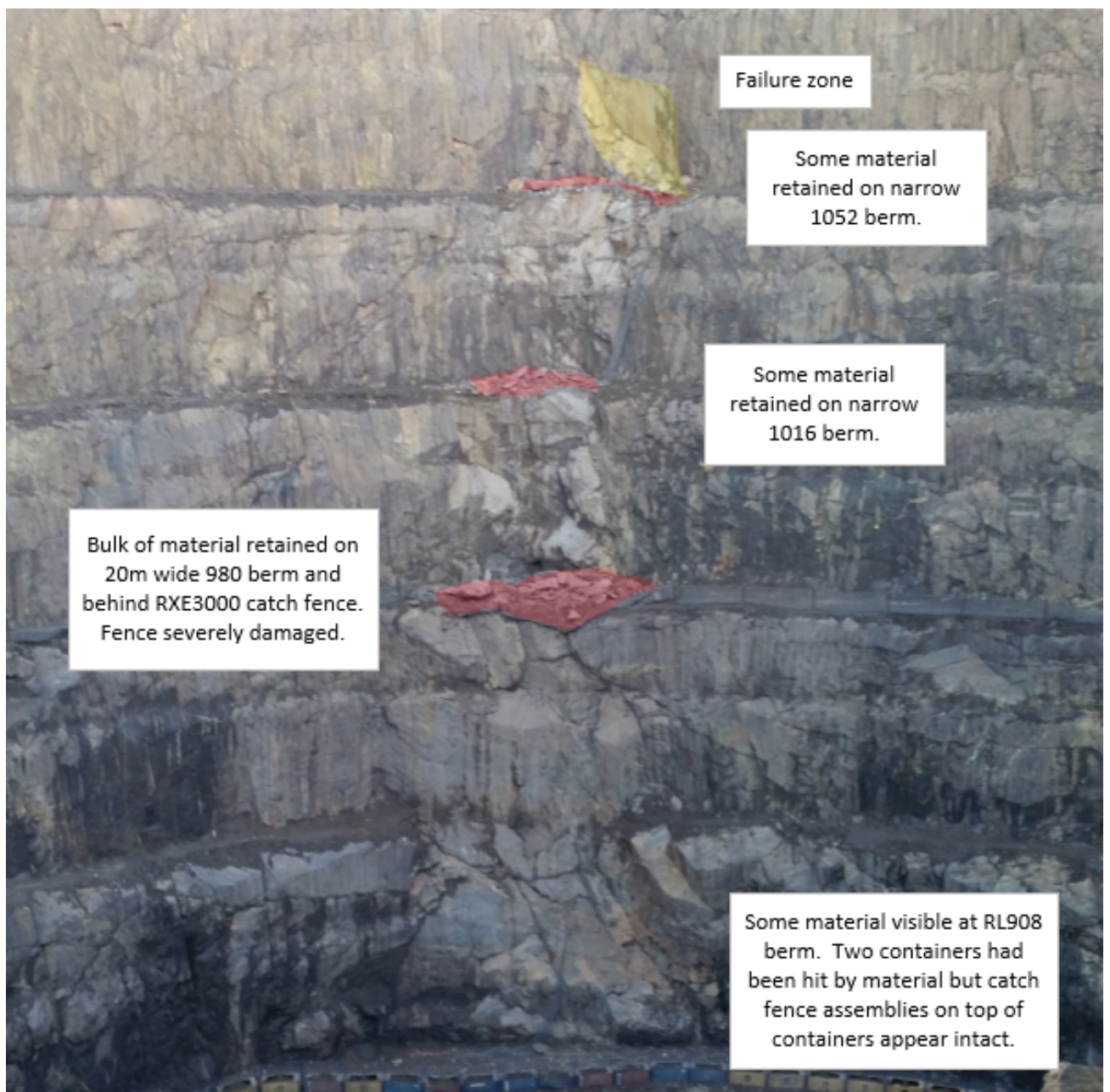

Figure 7 RF872 source and travel path

\section{$4 \quad$ West wall long-term dilation}

Despite the lack of continuity of monitoring and the use of different instruments scanning at various resolutions and positions, the data from the scans was compiled in PointStudio to look at long-term dilation, as shown in Figure 8. During the first two and a half years of monitoring, the main movements occurred in an area just beneath the main ramp, as can be seen in Figure 8, in the August 2018 plot. This area underwent five rockfall events of up to $100 \mathrm{t}$, all during rainfall periods. All of the rockfall materials were retained on the underlying berm/s and never reached the pit floor.

3D stress modelling using Flac3d (Lucas et al. 2020) suggested that the main area of expected movement was the 'bullnose' area (Figure 4). From the long-term progressive dilation records, one can see that significant movements did occur on the bullnose but much broader movements occurred to the south and lower down on the west wall of the pit wall.

\section{$5 \quad$ Structural mapping and relationships to dilation}

PointStudio had been used to remotely map the geological structure of the Giant Pit (Hutchison et al. 2018) but several through-going structures were not available in the time frame of the 2018 Flac3d modelling. When the final structural mapping is overlain on the dilation plot (Figure 9), one can see a direct correlation of distinct dilation movements to several of the major geological structures. These major structures are steeply inclined shear structures. In 2019, a third round of 3D stress modelling was undertaken which allowed these structures to be incorporated into the 2019 Fac3d model, as discussed by Lucas et al. (2020). 



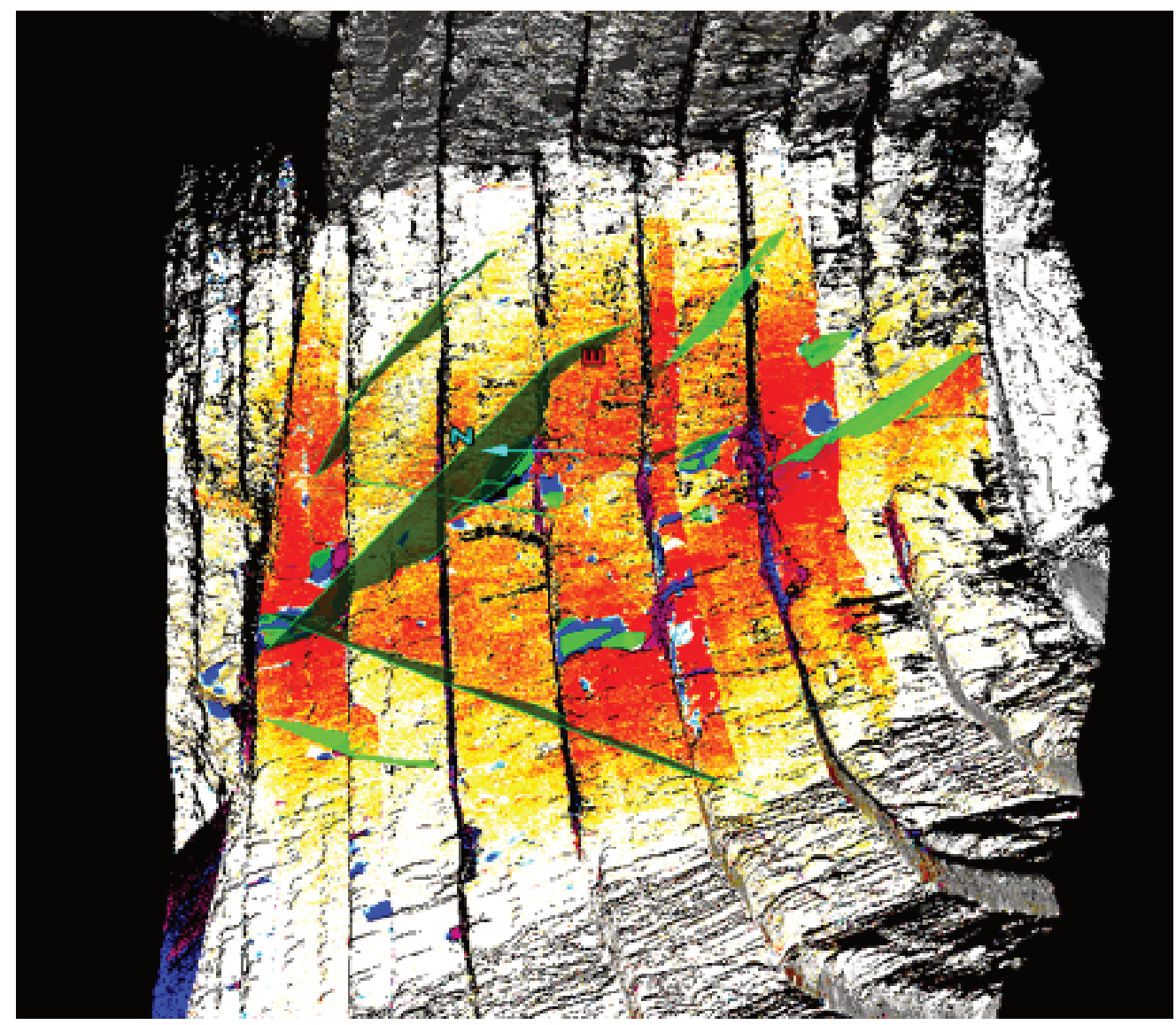

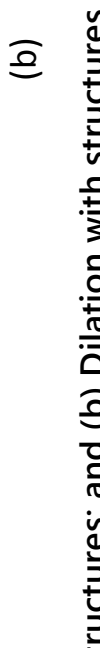

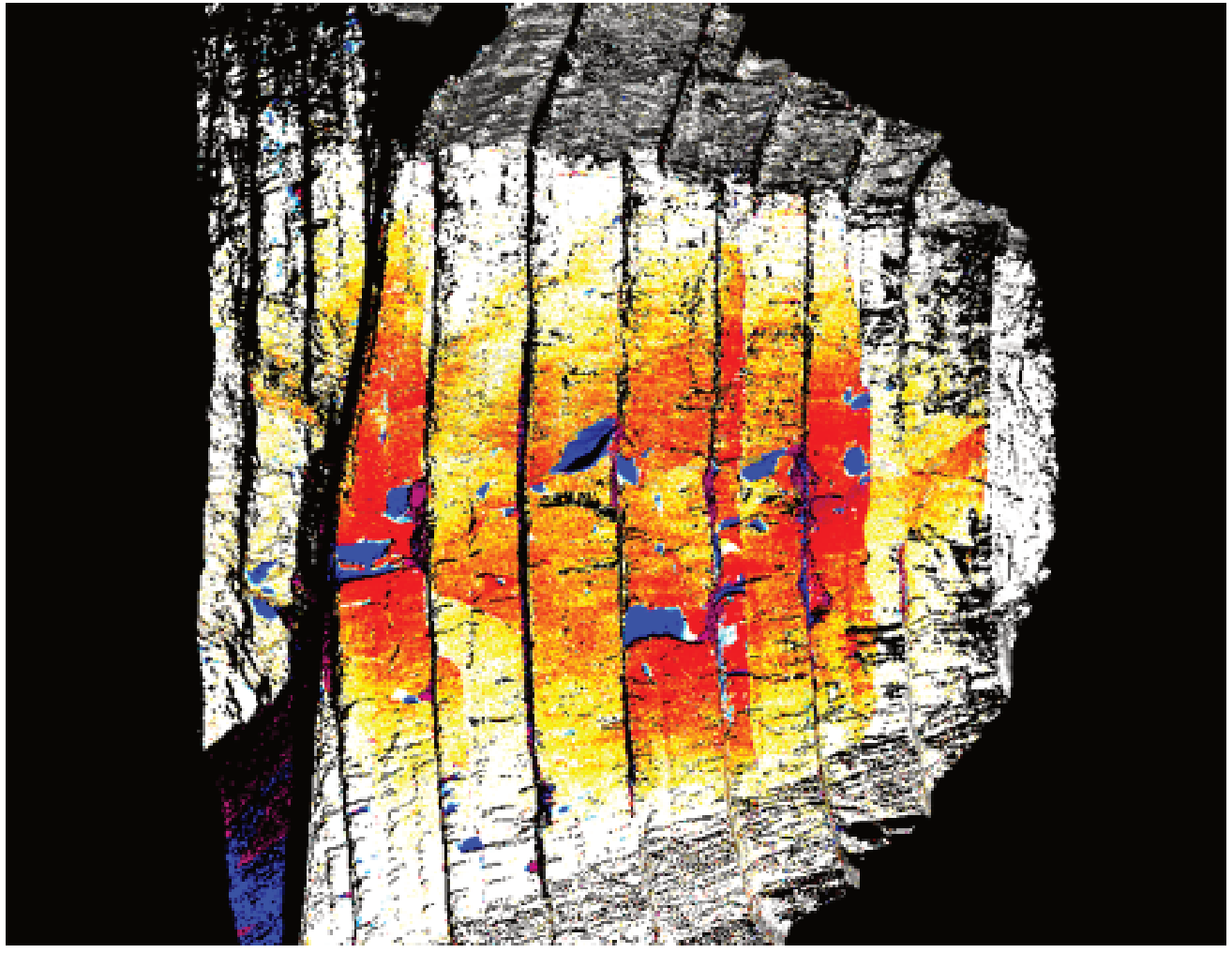




\section{$6 \quad$ Rockfall monitoring}

PointStudio allows comparison of DTMs to look for rockfalls that may not have been picked up by the Sentry monitoring, not physically observed at the time, or which may have occurred when personnel had evacuated the pit during heavy rainfall events. The PointStudio plots of Figures 8 and 9 show the larger rockfalls and slips as dark blue areas. Smaller rockfalls from a monthly plot can be seen in Figure 10. The rockfall areas are noted in dark or light blue, while the accumulated debris can be seen as red areas on the berms. The arrows on the image show several examples. Just below the second berm from the bottom of the image, two areas moved with the adjacent rockfalls but did not fall into the pit and show up in red meaning movement towards the scanner. These types of analyses were fundamental in building up the Kanmantoo rockfall register, used to manage rockfall risk as described in Hutchison et al. (2015).

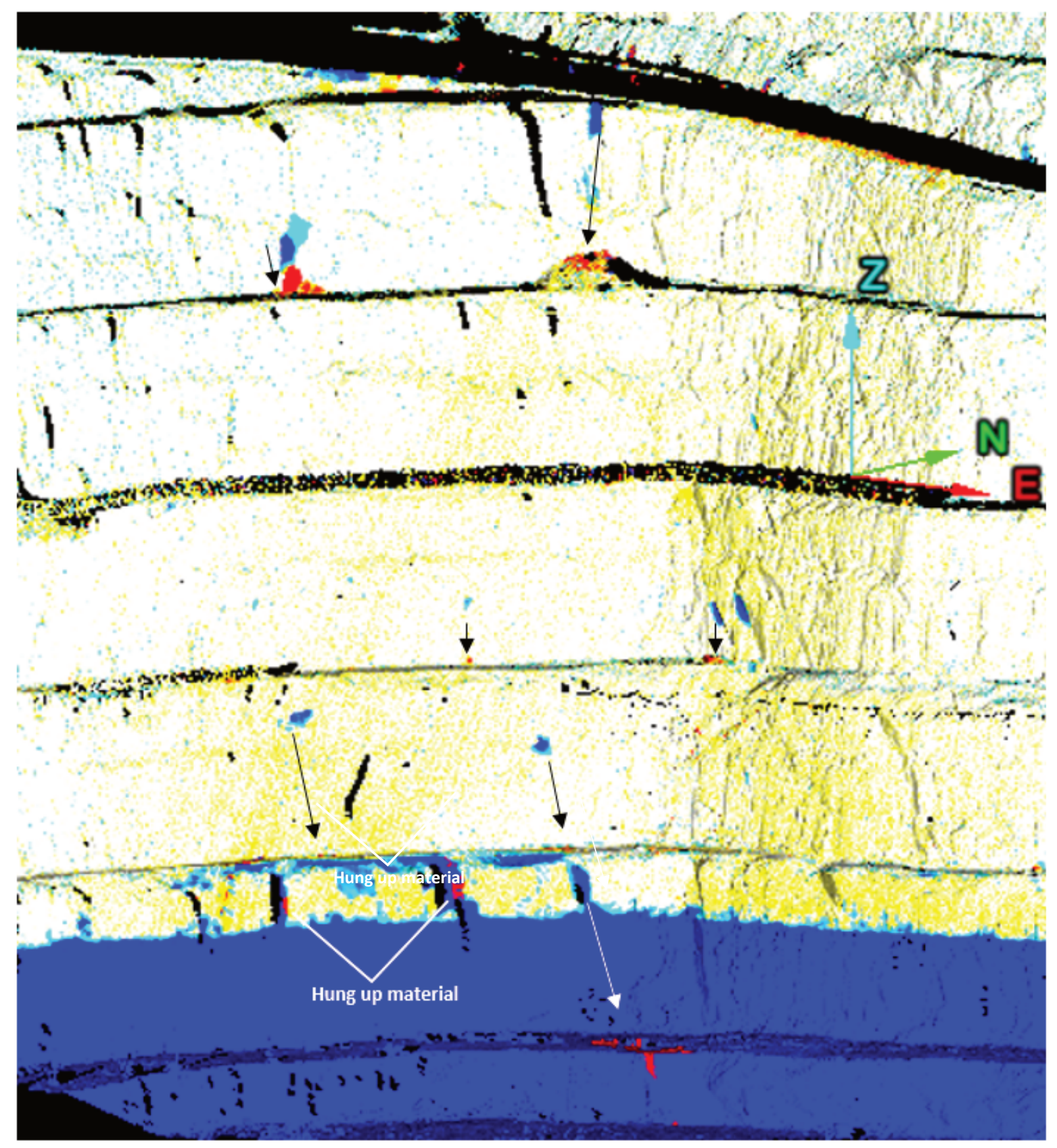

Figure 10 Small rockfalls identified from end of month analysis 


\section{Discussion}

Although the monitoring was carried out by a variety of laser scanners and from different locations, the robust nature of the scan data and the capability of the PointStudio software allowed the geotechnical team to tie together the complete picture of the Giant Pit west wall dilation history.

In reflection, the preferred long-term monitoring protocols for long-term dilation would include:

- A set crest monitoring station/s with as near-to-normal readings of the key area of monitoring.

- A single laser scanner, routinely recalibrated.

- One consistent scan project, with preferably scan res 8.

A multiple laser scanner crest setup would allow full pit monitoring.

\section{Conclusion}

Laser monitoring of the Giant Pit initially began as a research project but quickly became one of the main slope monitoring systems alongside an Ibis-FM slope stability radar. Sentry systems were used to successfully critically monitor several of the walls.

Despite the ad hoc nature of the earliest radar scans, the Point Studio software enabled the geotechnical staff to piece together thousands of individual scan records to map out the dilation history of the west wall. This data was used to calibrate and validate several 3D stress analyses. The detail provided by the res 8 scans allowed detailed structural mapping which also has been used to provide input into the 3D stress analysis.

\section{Acknowledgement}

The authors would like to thank HGO for allowing this paper to be published and to Maptek for collaborating with $\mathrm{HGO}$ in laser scanning research.

\section{References}

Hutchison, BJ, Chambers, J, Macqueen, G, Salas, E \& Huang, N 2015, 'The use of rockfall statistics in managing small rockfalls in two Australian open pit mines', Proceedings of the 2015 International Symposium on Slope Stability in Open Pit Mining and Civil Engineering, Southern African Institute of Mining and Metallurgy, Johannesburg.

Hutchison, BJ \& Howarth, J 2015, Kanmantoo Mine rockfall and rock wall failures: I-Site 8820 laser scanning applications, Proceedings of the 2015 International Symposium on Slope Stability in Open Pit Mining and Civil Engineering, Southern African Institute of Mining and Metallurgy, Johannesburg, pp. 546-562.

Hutchison, BJ, Chambers, J, Gannon, S \& Oko-oboh, D 2017, Case study of joint structure and the design and performance of open pit walls at the Kanmantoo Copper Mine, Proceedings of the Tenth International Mining Geology Conference 2017, Australasian Institute of Mining and Metallurgy, Melbourne.

Hutchison, BJ, Chambers, J, Richards, J \& Herrmann, J 2018, 'Mine Rockfall and Rock Wall Failures - Proven digital laser-based approach for monitoring slopes at the Kanmantoo Copper Mine', Proceedings of the Fourth Australasian Ground Control in Mining Conference, Australian Institute of Mining and Metallurgy, Melbourne.

Hutchison, BJ, Morrison, AT \& Lucas, D 2020, 'Steep Wall Mining - Engineered structures used in the management of rockfall hazards at Kanmantoo Copper Mine', in PM Dight (ed.), Proceedings of the 2020 International Symposium on Slope Stability in Open Pit Mining and Civil Engineering, Australian Centre for Geomechanics, Perth, pp. 825-842.

Lucas, DS, Vakili, A \& Hutchison, BJ 2020, Three-dimensional numerical modelling for successful design of steep slopes at the Kanmantoo Copper Mine, South Australia, in PM Dight (ed.), Proceedings of the 2020 International Symposium on Slope Stability in Open Pit Mining and Civil Engineering, Australian Centre for Geomechanics, Perth, pp. 1077-1090.

Maptek 2020, PointStudio, version 8 computer software, Adelaide, South Australia, Australia, https://www.maptek.com/ products/pointstudio/index.html 
